EPiC Series in Education Science
Volume 3, 2020, Pages 262-268
Proceedings of the MIT LINC 2019 Conference

\title{
Scandinavian students' perspective on learning from digital learning environment: The potential role of interactive quality
}

\author{
Mehwish Waheed, Liudvika Leisyte \\ Technische Universität Dortmund, Germany \\ mahwish.phd@gmail.com, liudvika.leisyte@tu-dortmund.de
}

\begin{abstract}
This research aims to identify the role of interactive quality to assess the Scandinavian students' perceived learning from the digital learning environment. The quantitative research methodology is used by utilizing the questionnaire as a survey tool by targeting the Scandinavian students who are using digital learning environment. The findings show that socialability based interactivity significantly influence the students' learning. The future directions and contributions are discussed in the concluding section.
\end{abstract}

\section{Introduction}

Institutions have invested their significant amount of capital for the digitization of conventional education paradigm - still failures are high, and it is not giving the expected outcomes (Masoumi and Lindström, 2012). It is noted that studies have reported on the implementation of blended learning (Graham et al., 2013), the role of information quality (Alkhattabi et al., 2011) and internal psychological process (Wan et al., 2008) in an eLearning environment. Indeed, investigating the quality of information and implementation process are important factors. However, it is equally important to take account of the interaction among students and with the platform. The digital environment provides a unique platform for students where they gather virtually and communicate through interactive online services. This study argues that the quality of interaction either with the fellow peers or the platform (Yeh et al., 2011) helps in students' learning. It is suggested to integrate the interactive quality in the behavioural model of the digital learning environment. Therefore, this study fills the 
gap and investigates the potential role of interactive quality (Platform-based, Sociability-based) to achieve the desired learning from the DLe.

\section{Research Framework}

In a Digital Learning Environment (DLe), students' make their social network and interact via different applications and functions. Interactivity is supported by the wise use of the online interface, available navigational features, and services. Yeh et al. (2011) mentioned the two-dimensions (platform-based interactivity and sociabilitybased interactivity) to judge the interactive quality in a virtual world context. In a digital learning context, an application that improves the sense of communication direction, control over the content, respond to information requests work as tools to enhance platform-based interactive quality. While sociability-based interactive quality can be achieved by having ease of communication with time flexibility, sense of place, interactive two-way communication, and desired results after communication.

This study acknowledges the multi-dimensional nature of interactive quality and argues that the student's evaluation of the platform-based (student's interaction with the platform) and sociability-based (student's interaction with other students) interactivity determine the quality of interaction. Subsequently, in the learning process, the interactive quality would probably influence the student's learning. Where, perceived learning is students' self-evaluation to assess their knowledge gain or learning from any system of the environment (McGill and Klobas, 2009, Waheed et al., 2016).

Inferring from the above explanation, this study proposes a structural relationship between Platform-based interactive quality and Sociability-based interactive quality and perceived learning and postulates the following two hypotheses:

Hypothesis 1. Platform-based interactive quality influences the students' perceived learning from the DLe.

Hypothesis 2. Sociability-based interactive quality influences the students' perceived learning from the DLe.

\section{Methodology}

The data was collected from four public sector universities in Sweden. Sweden was selected because of technological advancement and significant investment in higher education, research and technological innovations - and being at the lead in EU (Sadurskis, 2016). Participants $(n=78)$ included postgraduate students registered in online Masters' programs. Program coordinators facilitated the researcher for the distribution of five-point Likert scale survey questionnaire. The items were extracted from prior validated scales - interactive quality Yeh et al. (2011), perceived learning 
Lee et al. (2010). This study is a part of a bigger project that does a comparative study of Swedish and German DLe, Sponsored by Alexander Von Humboldt Foundation, Germany. The project span is from July 2016 - June 2019; therefore, the initial finalized data from Swedish universities are presented in this paper.

\section{Results}

The SmartPLs and IBM SPSS V25 were used to test the proposed hypothesis and highlight the respondents' descriptive statistics.

\subsection{Descriptive Statistics}

The clustered bar count shows that there was a number of male respondents (24.4\%) as compared to female $(20.5 \%)$ and the great majority was between the age group of 24-30 years (See Fig. 1).

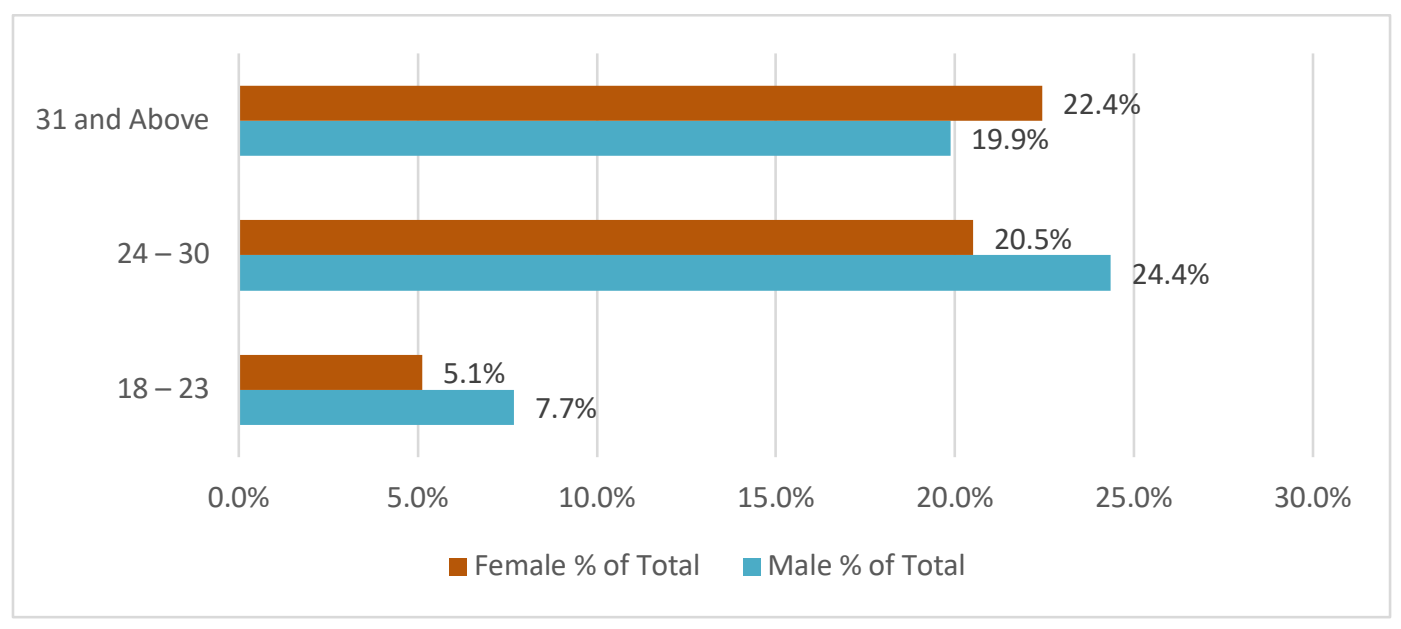

Figure 1. Clustered Bar count of Age by Gender

The Cross-tabulation of problems faced by students enrolled in different semesters while using DL environment shows that inadequate training is the major issue for the students $(21.1 \%)$ followed by broken links (13,0\%), and login issues $(5.7 \%)$ enrolled in the $2^{\text {nd }}$ and $4^{\text {th }}$ semester (See Fig 2). 


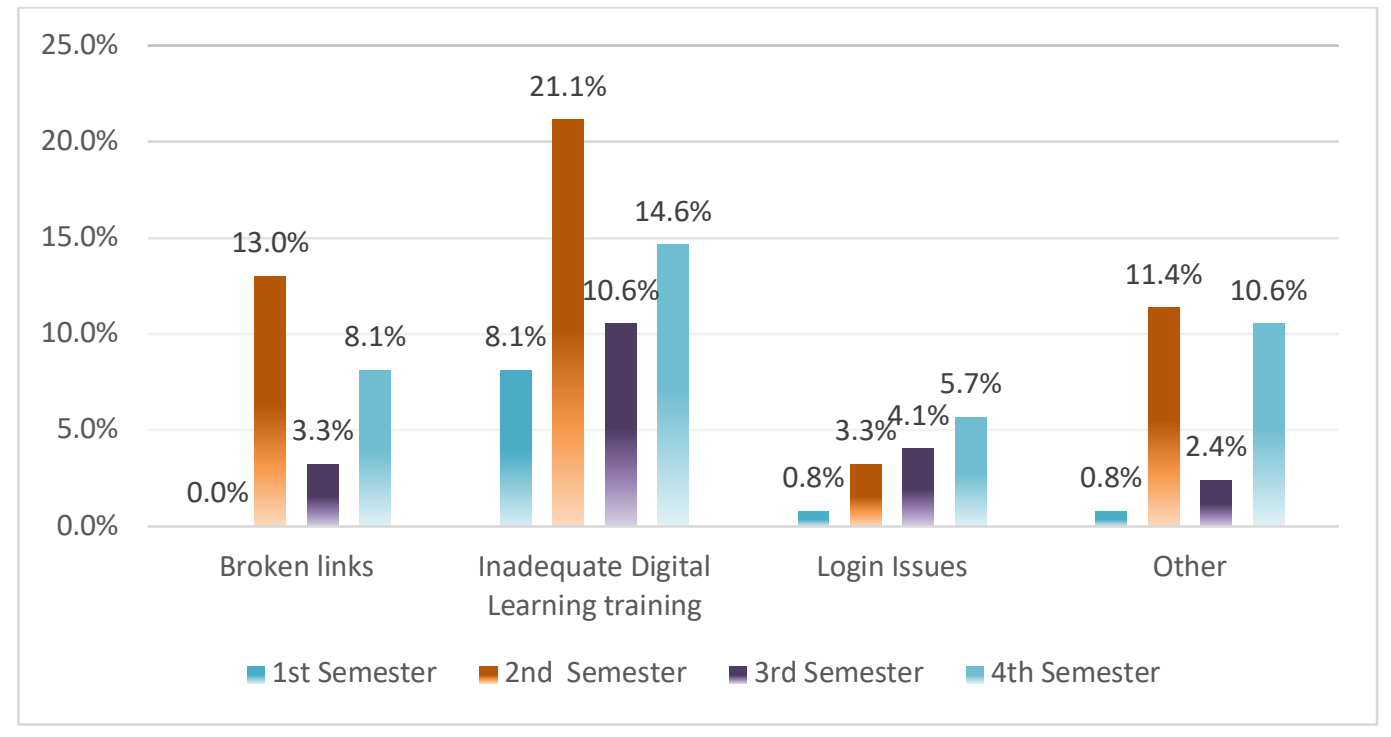

Figure 2. Cross Tabulation of Semester Enrolled \& Problems using DLe

The pie chart shows that Trial and error method is used by several students (62.0\%) to understand DLe, while $18 \%$ learn by supervisor guidance (See Fig 3).

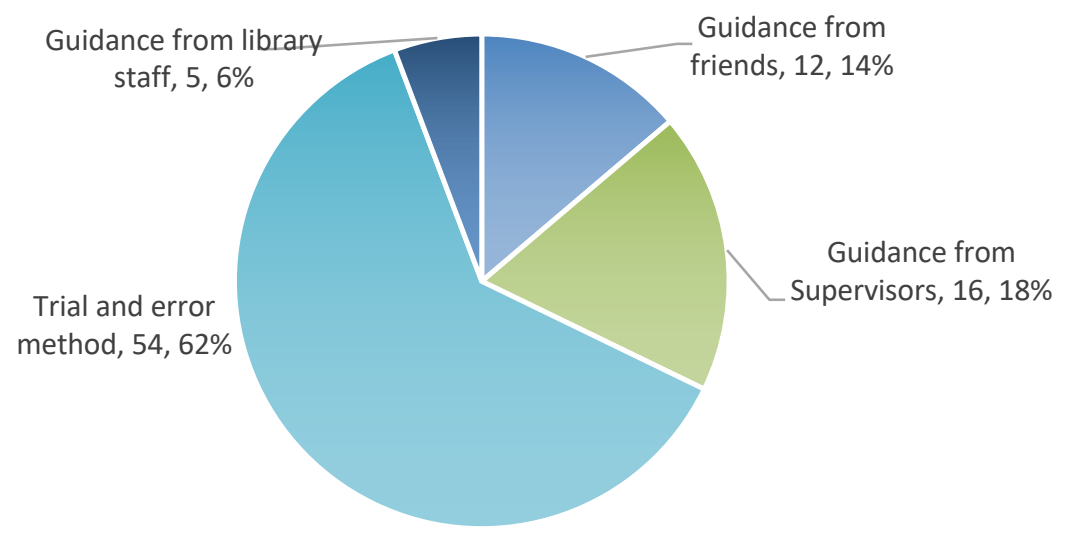

Figure 3. Source of learning DLe

The result shows that the majority of students use DL environment for content downloading (33.3\%) followed by Assignments (32.1\%) and discussion forums (19.2\%) (See Figure 4). 


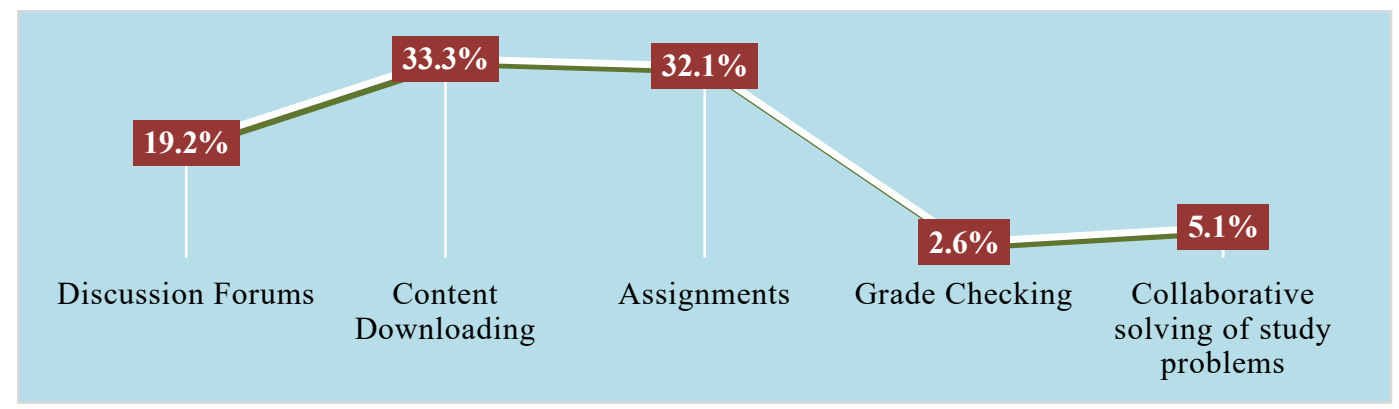

Fig 4. Activity Performed in DLe

\subsection{Reliabilities, Collinearity, and Hypothesis}

Cronbach's Alpha $(\alpha)$ coefficient value for all constructs was above the suggested threshold, i.e. 70 (Hair et al., 2016) that suggest adequate reliability. The bivariate Pearson correlation analysis presents a significant correlation $(p<.001)$ among platform-based interactivity, sociability-based interactivity, and perceived learning. The Variance Inflation Factor (VIF) and the associated tolerance values were within the acceptable range of VIF $<10$ and Tolerance $>.1$ (Hair et al., 2016), which shows that there were no multicollinearity issues between platform-based interactivity, sociability-based interactivity and perceived learning.

The two dimensions of interactive quality, i.e. Platform-based interactivity and Sociability -based interactivity were regressed on perceived learning to evaluate the structural relationship between proposed variables. The test of PLs Algorithm and bootstrapping was applied on the proposed model to get the effect size and significance levels, respectively.

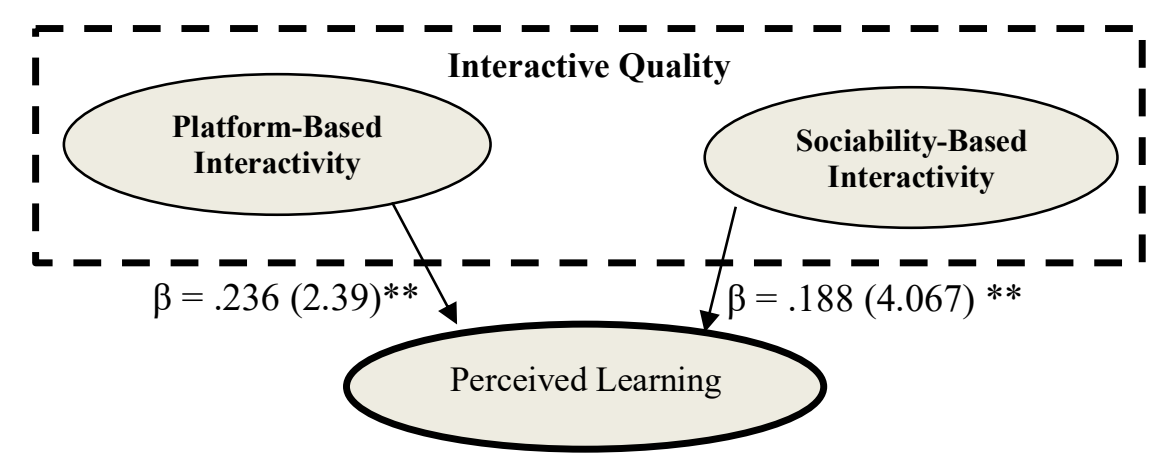

Figure 5. Results of the proposed hypothesis (t-values in brackets show significance level) 
The findings from the data show that Platform-based interactivity has a significant influence on students perceived learning. The relationship is significant with the effect size of $\beta=.236$ and significant at $\mathrm{P}<.001$ (after bootstrapping result of $t=2.39$ ). Therefore, the first hypothesis is supported. A significant relationship between Sociability -based interaction was noted that supported the second hypothesis. Sociability -based interactivity had the effect of $\beta=.188$ and significant at $\mathrm{p}<.001(\mathrm{t}=$ 4.067) and accounted for $10 \%$ of the variance in student's perceived learning $\Delta \mathrm{R}^{2}=$ .102) (See Figure 5).

\section{Conclusion}

This study is one such endeavour that has taken a step forward to investigate the students' learning from the DLe. It contributes towards the excellence of European institutions - where it is suggested that the provision of quality interaction not only enhance performance and learning but will also build a positive long-term relationship between students and DLe. The findings show that Swedish students are apparently satisfied from platform-based interactive quality - the plausible reason could be that they have full control over the DLe in terms of selecting information, functions or services based on their needs, therefore significant impact on their learning was found. However, the significant relationship between socialaility based interactivity and perceived learning demonstrate the students have ease of communication with time flexibility that significantly influences their learning. As an empirical contribution, this study provides a general framework that helps in understanding the quality of interaction that improve the students' learning from the digital learning environment and avoid impairment of knowledge flow. 


\section{References}

ALKHATTABI, M., NEAGU, D. \& CULLEN, A. 2011. Assessing information quality of e-learning systems: a web mining approach. Computers in Human Behavior, 27, 862-873.

GRAHAM, C. R., WOODFIELD, W. \& HARRISON, J. B. 2013. A framework for institutional adoption and implementation of blended learning in higher education. The Internet and Higher Education, 18, 4-14.

HAIR, J. F., HULT, G. T. M., RINGLE, C. \& SARSTEDT, M. 2016. A Primer on Partial Least Squares Structural Equation Modeling (PLS-SEM), Thousand Oaks, CA, Sage.

LEE, E. A.-L., WONG, K. W. \& FUNG, C. C. 2010. How does desktop virtual reality enhance learning outcomes? A structural equation modeling approach. Computers \& Education, 55, 1424-1442.

MASOUMI, D. \& LINDSTRÖM, B. 2012. Quality in e-learning: a framework for promoting and assuring quality in virtual institutions. Journal of Computer Assisted Learning, 28, 27-41.

MCGILL, T. J. \& KLOBAS, J. E. 2009. A task-technology fit view of learning management system impact. Computers \& Education, 52, 496-508.

SADURSKIS, A. 2016. Higher Education in Sweden. In: AMFT, A. (ed.). Stockholm, Sweden.

WAHEED, M., KAUR, K. \& KUMAR, S. 2016. What role does knowledge quality play in online students' satisfaction, learning and loyalty? An empirical investigation in an eLearning context. Journal of Computer Assisted Learning.

WAN, Z., WANG, Y. \& HAGGERTY, N. 2008. Why people benefit from elearning differently: The effects of psychological processes on e-learning outcomes. Information \& Management, 45, 513-521.

YEH, N.-C., CHUAN-CHUAN LIN, J. \& LU, H.-P. 2011. The moderating effect of social roles on user behaviour in virtual worlds. Online Information Review, 35, 747-769. 